Supporting Information for

\title{
Catalyst-Free Selective Oxidation of Diverse Olefins to Carbonyls with High Yield Enabled by Light under Mild Conditions
}

Weiwei Yu and Zhongkui Zhao*

State Key Laboratory of Fine Chemicals, PSU-DUT Joint Center for Energy Research,

School of Chemical Engineering, Dalian University of Technology,

Dalian 116024, P. R. China.

\section{Table of Contents}

1. General Information

2. Optimization of Reaction Conditions

3. Preparation and Characterization of Products $\mathbf{1 b}-\mathbf{1 0 b}$

4. Gram-Scale Synthesis of $\mathbf{1 b}$

5. Supplementary Charactrization and Informantion

6. References 


\section{General Information}

Solvents used in these experiments were reagent grade or better and deionized water was used for all experiments. The conversion and the selectivity of products were detected by gas chromatography (GC 9790 II, FuLi Instruments) and the qualitative analysis were performed by gas chromatography-mass spectrometry (GC-MS, HP6890/5973MSD and 7000B, Agilent). Flash column chromatography was performed using Qingdao Makall Silica Gel (particle size 200-300 mesh) and columns were packed according to the dry method and equilibrated with the appropriate eluent prior to use. HPLC grade solvents were used and the solvent mixtures used as eluent are understood as volume/volume. UV-Vis absorption spectra were recorded on a MACY V-1500PC Ultraviolet-visible spectrophotometry. The electron paramagnetic resonance (EPR) spectra were performed on a Bruker A200 spectrometer and the DMPO as free radical trapping agent.

\section{Materials}

Acetonitrile $\left(\mathrm{CH}_{3} \mathrm{CN}\right)$ and tetrahydrofuran were purchased from Tian in Fuyu Fine Chemical Co. Ltd. Styrene $\left(\mathrm{C}_{8} \mathrm{H}_{8}\right)$ and hydrogen peroxide $\left(\mathrm{H}_{2} \mathrm{O}_{2}, 30 \%\right)$ were gained from Tianjin Damao Chemical Reagent Factory. 5,5-dimethyl-1-pyrroline N-oxide (DMPO), tert butyl alcohol (TBA), 4-benzoquinone (BQ) and allybenzene (CAS: 300-57-2) were provided by Aladdin. Ethyl alcohol was obtained from Tianjin Dongli District Tianjin University Chemical Reagent Factory. Acetone was purchased from Tianjin Third Chemical Reagent Factory. 4-chlorostyrene (CAS: 1073-67-2), 2-chlorostyrene (CAS: 2039-87-4), 3-chlorostyrene (CAS: 2039-85-2), 4-methylstyrene (CAS: 622-97-9), 4-bromostyrene (CAS: 2039-82-9), 4-fluorostyrene (CAS: 405-99-2) and 2-phenyl-1-propene (CAS: 98-83-9) were provided by Energy Chemical. 1,1-diphenylethylene (CAS: 530-48-3) was synthesized according to our previous work. ${ }^{1}$ 


\section{Optimization of Reaction Conditions}

\section{Screening of solvents}<smiles>C=Cc1ccccc1</smiles>

1a $0.1 \mathrm{mmol}$<smiles>O=Cc1ccc(C(CO)OS(=O)(=O)O)cc1</smiles>

$1 b$

$0.1 \mathrm{mmol} 1 \mathrm{a}, 1 \mathrm{ml}$ solvent $\left(\mathrm{CH}_{3} \mathrm{CH}\right.$, THF, EtOH, acetone and the mixture of $0.6 \mathrm{ml}$ $\mathrm{CH}_{3} \mathrm{CH}$ and $0.4 \mathrm{ml} \mathrm{H} \mathrm{H}_{2} \mathrm{O}$ ) and $1.2 \mathrm{mmol} \mathrm{H}_{2} \mathrm{O}_{2}$ were sealed into a $10 \mathrm{ml}$ flask. Subsequently, the mixture was illuminated by the high pressure mercury lamp (Shanghai Jiguang special lighting electric appliance factory, GGZ 175) for a period of time with continuous stirring. The reaction temperature was kept at $20{ }^{\circ} \mathrm{C}$ by a circulating bath and an air fan. The conversion and the selectivity of $\mathbf{1 b}$ were detected by gas chromatography.

\section{Concentration of $\mathrm{H}_{2} \mathrm{O}_{2}$ effects}

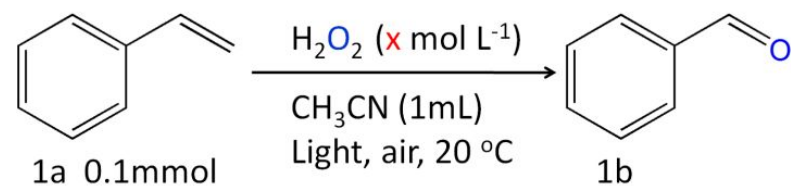

$0.1 \mathrm{mmol} \mathrm{1a}, 1 \mathrm{ml} \mathrm{CH}{ }_{3} \mathrm{CH}$ and a certain amount of $\mathrm{H}_{2} \mathrm{O}_{2}$ were sealed into a $10 \mathrm{ml}$ flask. Subsequently, the mixture was illuminated by the high pressure mercury lamp for $4 \mathrm{~h}$ with continuous stirring. The reaction temperature was kept at $20{ }^{\circ} \mathrm{C}$ by a circulating bath and an air fan. The conversion and the selectivity of $\mathbf{1 b}$ were detected by gas chromatography.

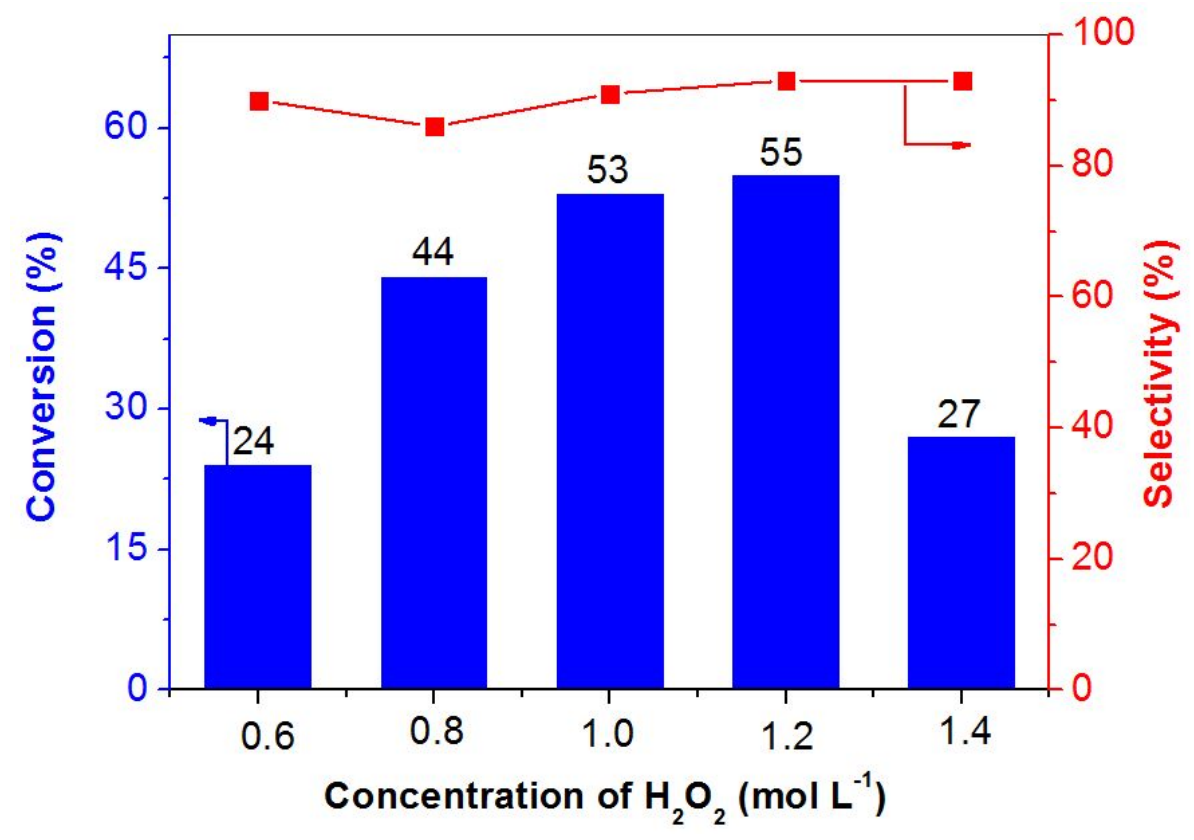

Figure S1. The effect of concentration of $\mathrm{H}_{2} \mathrm{O}_{2}$ on oxidation of 1a. Reaction condition unless otherwise noted: $0.1 \mathrm{mmol} \mathbf{1 a}, 1 \mathrm{ml} \mathrm{CH}{ }_{3} \mathrm{CN}$, air, $20^{\circ} \mathrm{C}$, $4 \mathrm{~h}$, and $\mathrm{UV}$ light. 
The results for the effect of $\mathrm{H}_{2} \mathrm{O}_{2}$ concentration on the selective oxidation of olefins are presented in Figure S1. The conversion of 1 a obviously increases from $24 \%$ to $55 \%$ along with the enlarging concentration of $\mathrm{H}_{2} \mathrm{O}_{2}$ from 0.6 to $1.2 \mathrm{~mol} \mathrm{~L}^{-1}$. The selectivity also shows a slight increase during this process concerning the increase in $\mathrm{H}_{2} \mathrm{O}_{2}$ concentration. However, a further increase in $\mathrm{H}_{2} \mathrm{O}_{2}$ concentration from 1.2 to 1.4 mol L-1 results in a dramatically decreased conversion from 55 to $27 \%$. This negative effect may be because the as-formed hydroxyl radical $(\cdot \mathrm{OH})$ from decomposition of $\mathrm{H}_{2} \mathrm{O}_{2}$ reacts with the extra $\mathrm{H}_{2} \mathrm{O}_{2}$ to produce $\cdot \mathrm{OH}_{2}$, and then $\mathrm{OH}$ will reacts with $\cdot \mathrm{OH}_{2}$ to produce $\mathrm{H}_{2} \mathrm{O}$ and $\mathrm{O}_{2}$ or dimerize to $\mathrm{H}_{2} \mathrm{O}_{2}$ in high concentration of $\mathrm{H}_{2} \mathrm{O}_{2}$, this will significantly reduce the utilization efficiency of $\mathrm{H}_{2} \mathrm{O}_{2}{ }^{2}$

\section{Solvent volume effects}

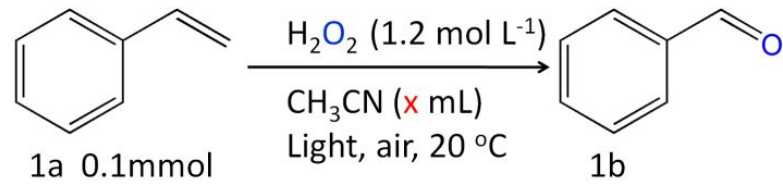

$0.1 \mathrm{mmol} \mathrm{1a}$, various volume of $\mathrm{CH}_{3} \mathrm{CH}$ and $1.2 \mathrm{mmol} \mathrm{H}_{2} \mathrm{O}_{2}$ were sealed into a $10 \mathrm{ml}$ flask. Subsequently, the mixture was illuminated by the high pressure mercury lamp for $4 \mathrm{~h}$ with continuous stirring. The reaction temperature was kept at $20{ }^{\circ} \mathrm{C}$ by a circulating bath and an air fan. The conversion and the selectivity of $\mathbf{1 b}$ were detected by gas chromatography.

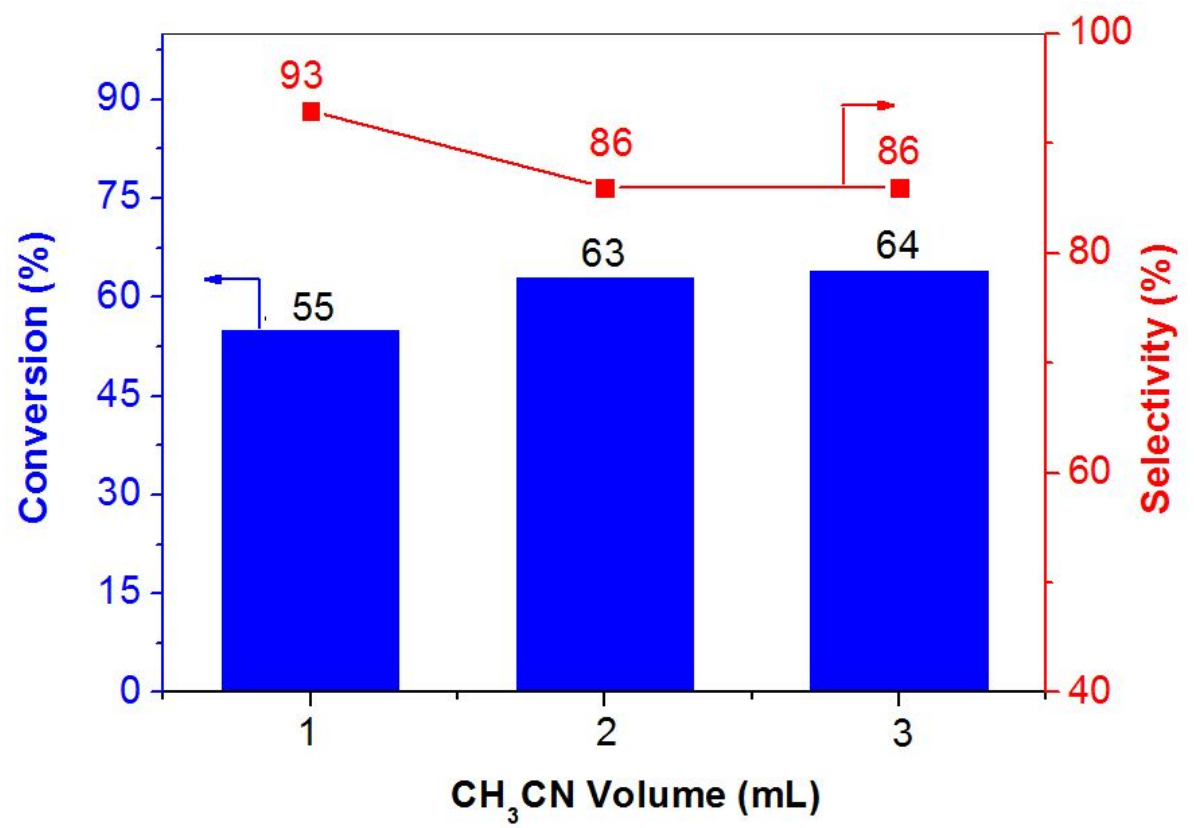

Figure S2. The effect of solvent $\left(\mathrm{CH}_{3} \mathrm{CN}\right)$ volume on the selective oxidation of 1a. Reaction condition unless otherwise noted: $0.1 \mathrm{mmol} \mathrm{1a}, 1.2 \mathrm{mmol}_{2} \mathrm{O}_{2}$, air, $20^{\circ} \mathrm{C}, 4 \mathrm{~h}$, and UV light.

The effect of solvent $\left(\mathrm{CH}_{3} \mathrm{CN}\right)$ volume on selective oxidation of olefins was studied. From Figure S2, with the increase of solvent volume, the conversion of 1a increases slightly, 
but the selectivity decreases from 93 to $86 \%$. Considering the efficient utilization of substrate, economic and environmental issue, ideal choice is lowest solvent usage $(1 \mathrm{~mL})$ and highest product selectivity.

\section{Preparation and Characterization of Products $1 \mathrm{~b}-\mathbf{1 0 b}$}

\section{General procedure for preparation of Products 1b-10b}

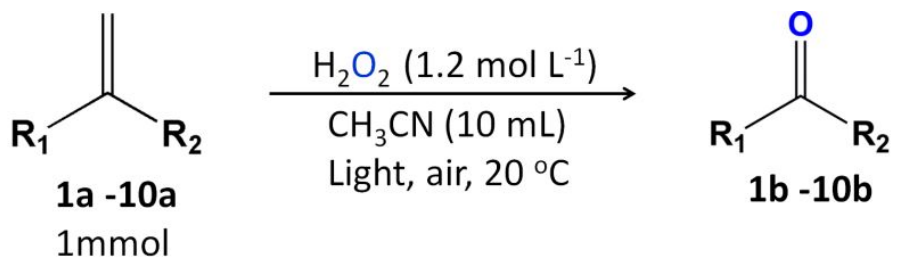

Representative example at $1 \mathrm{mmol}$ scale: $1 \mathrm{mmol} \mathbf{1 a - 1 0 a}, 10 \mathrm{ml} \mathrm{CH}_{3} \mathrm{CH}$ and $12 \mathrm{mmol}$ $\mathrm{H}_{2} \mathrm{O}_{2}$ were sealed into a $50 \mathrm{ml}$ flask. Subsequently, the mixture was illuminated by the high pressure mercury lamp for a period of time with continuous stirring. The reaction temperature was kept at $20^{\circ} \mathrm{C}$ by a circulating bath and an air fan. The conversion and the selectivity of 1b-10b were detected by gas chromatography. The crude products were purified by flash column chromatography using Qingdao Makall Silica Gel (particle size 200-300 mesh) to give desired carbonyls and hexane/ ethyl acetate $(\mathrm{AcOEt})=20 / 1$ as eluent.

\section{Benzaldehyde ${ }^{5}$ (1b)}<smiles>O=Cc1ccccc1</smiles>

The desired product $\mathbf{1 b}$ was colorless liquid (93\% isol. yield, $98.7 \mathrm{mg}$ ). Purification by flash chromatography using hexane/AcOEt (20/1) as eluent.

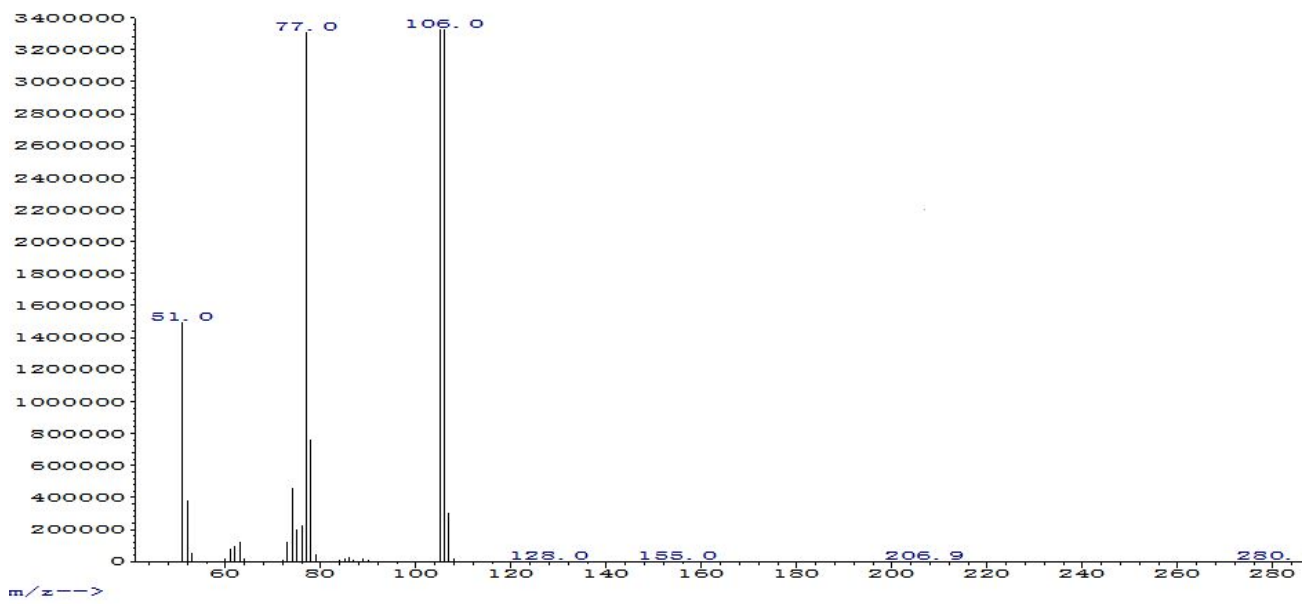




\section{4-Fluorobenzaldehyde ${ }^{5}(2 b)$}
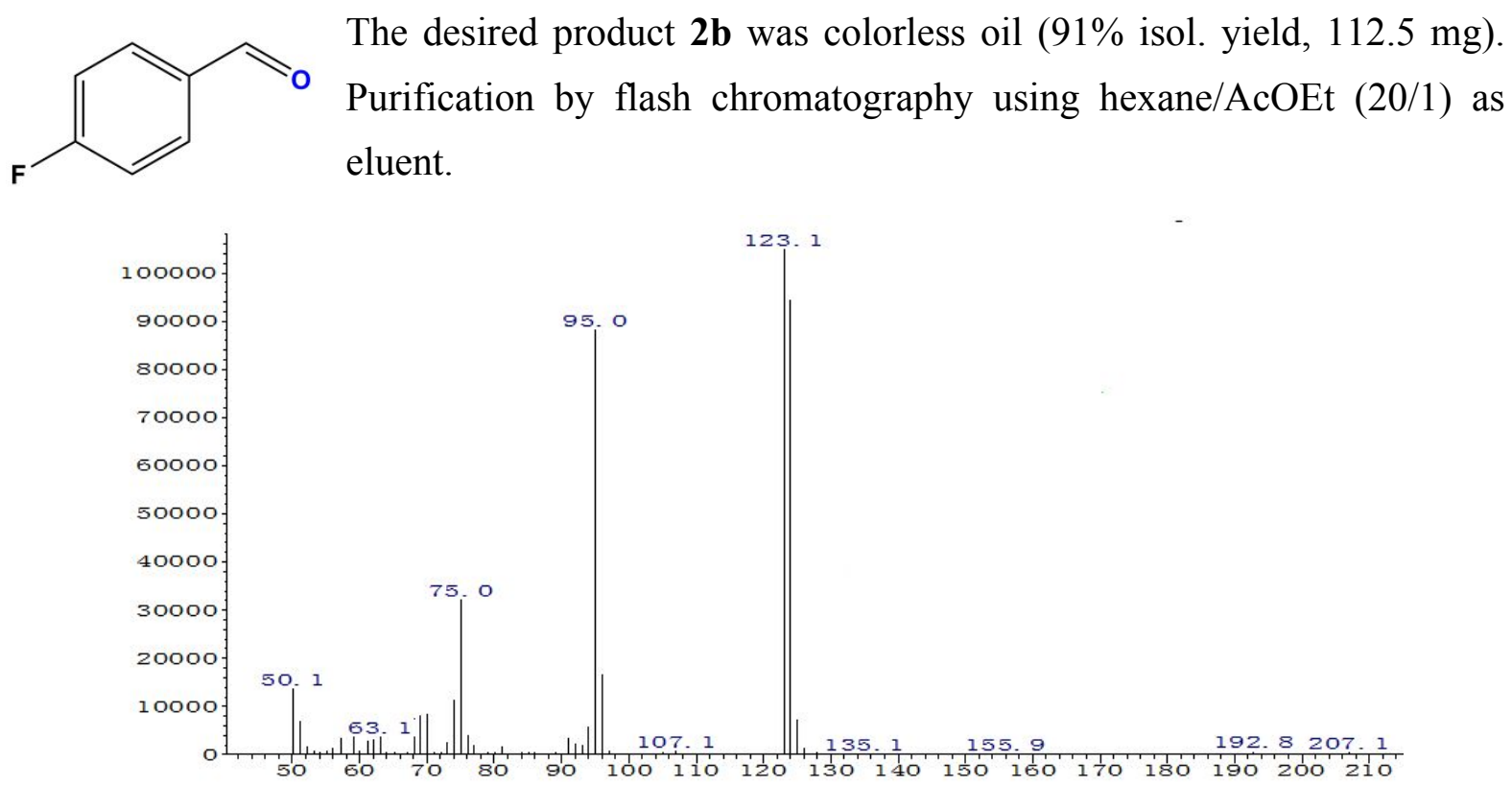

\section{2-Chlorobenzaldehyde ${ }^{5}(3 \mathrm{~b})$}<smiles>O=Cc1ccccc1Cl</smiles>

The desired product $\mathbf{3 b}$ was colorless liquid (79\% isol. yield, $110.9 \mathrm{mg}$ )

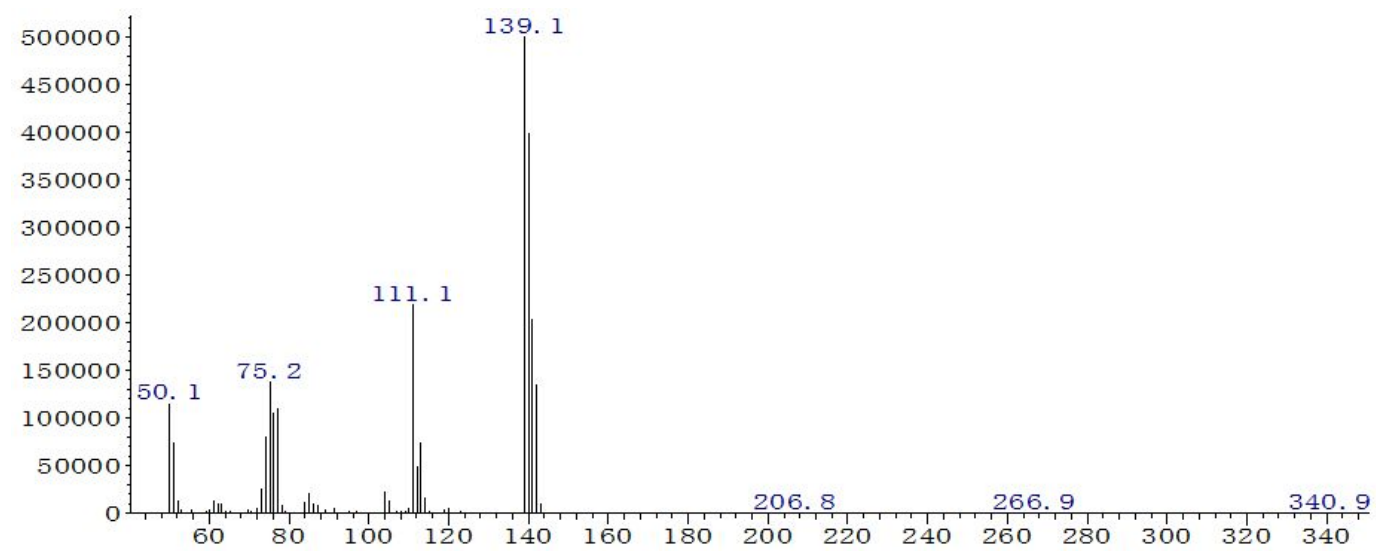




\section{3-Chlorobenzaldehyde 5 (4b)}<smiles>O=Cc1cccc(Cl)c1</smiles>

The desired product $\mathbf{4 b}$ was colorless liquid (85\% isol. yield, 119.6 mg). Purification by flash chromatography using hexane/AcOEt (20/1) as eluent.

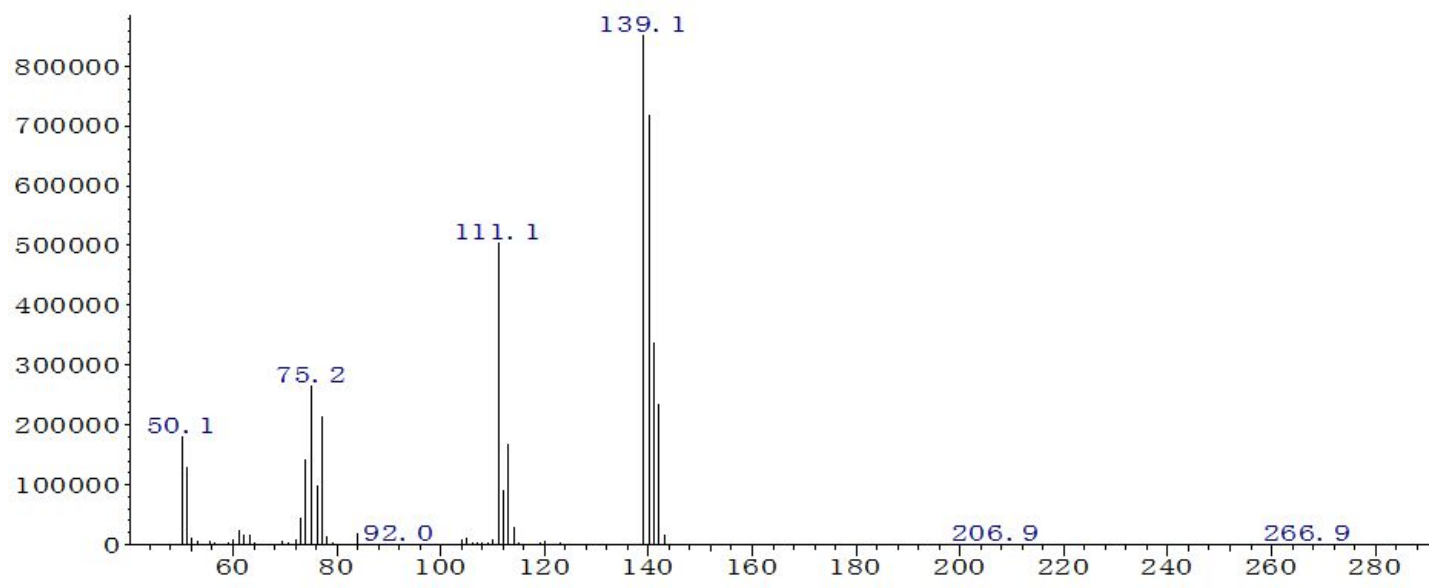

\section{4-Chlorobenzaldehyde ${ }^{5}$ (5b)}
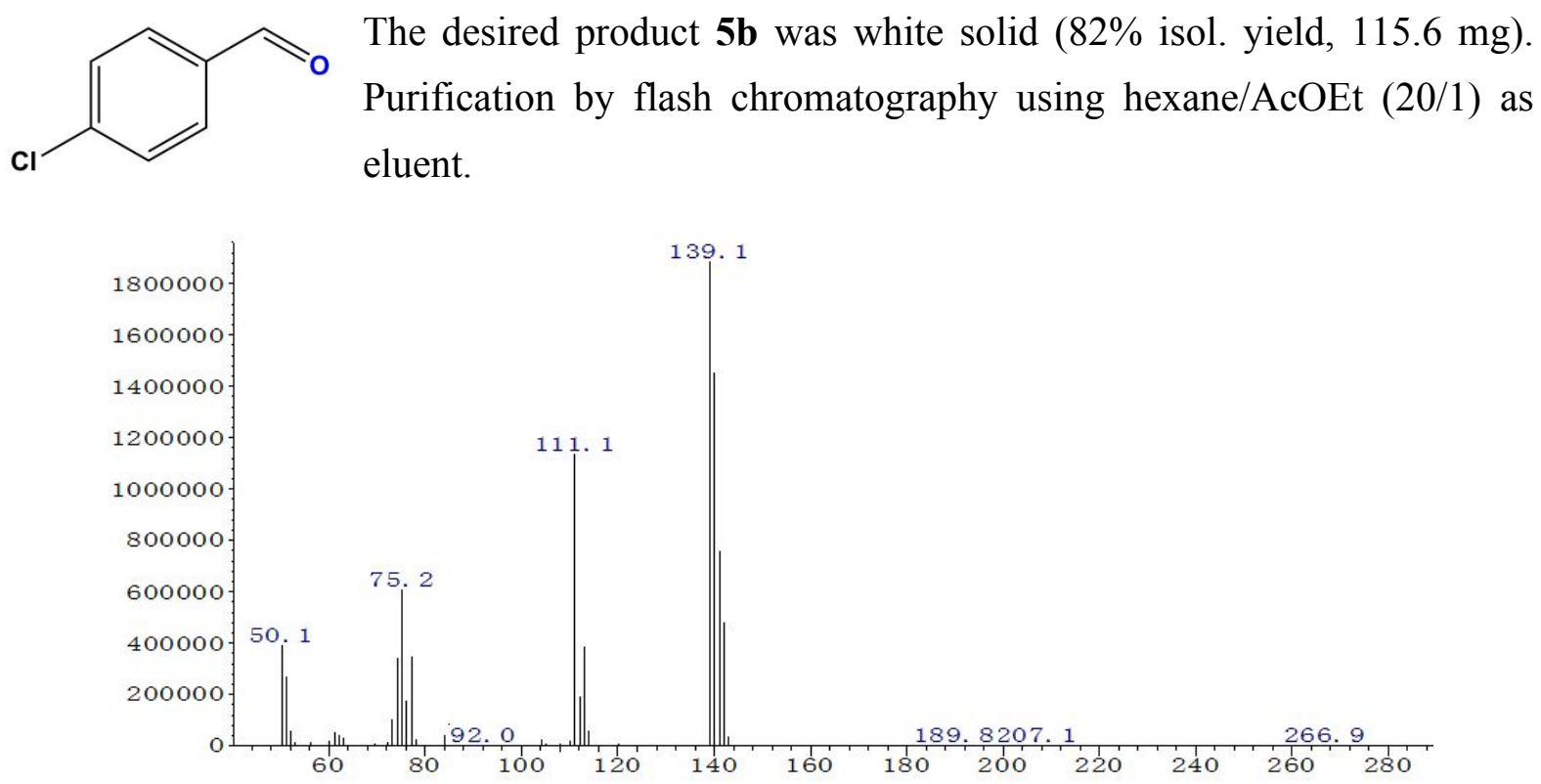


\section{4-Bromobenzaldehyde ${ }^{5}(6 b)$}
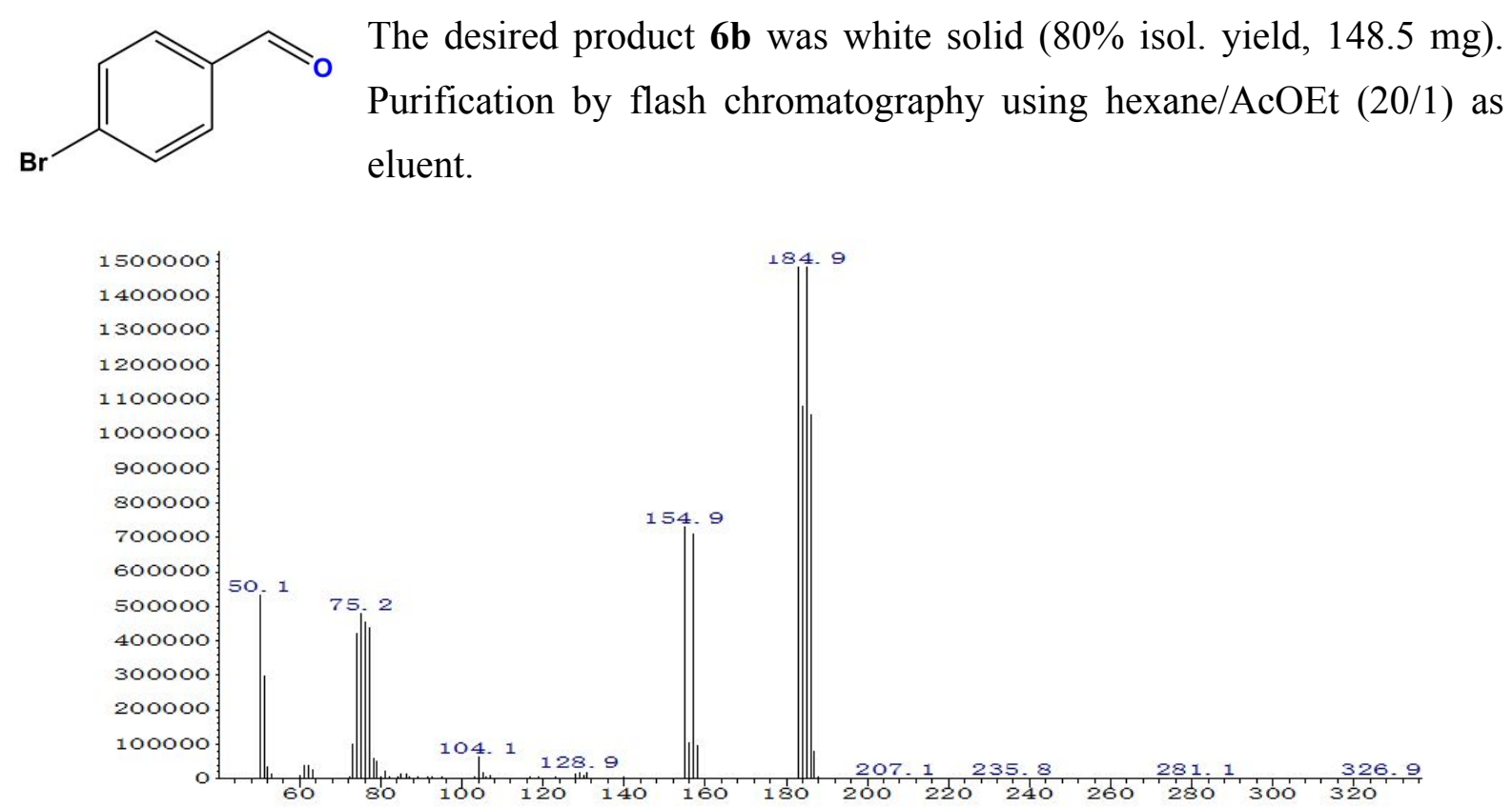

\section{4-Methylbenzaldehyde ${ }^{5}$ (7b)}
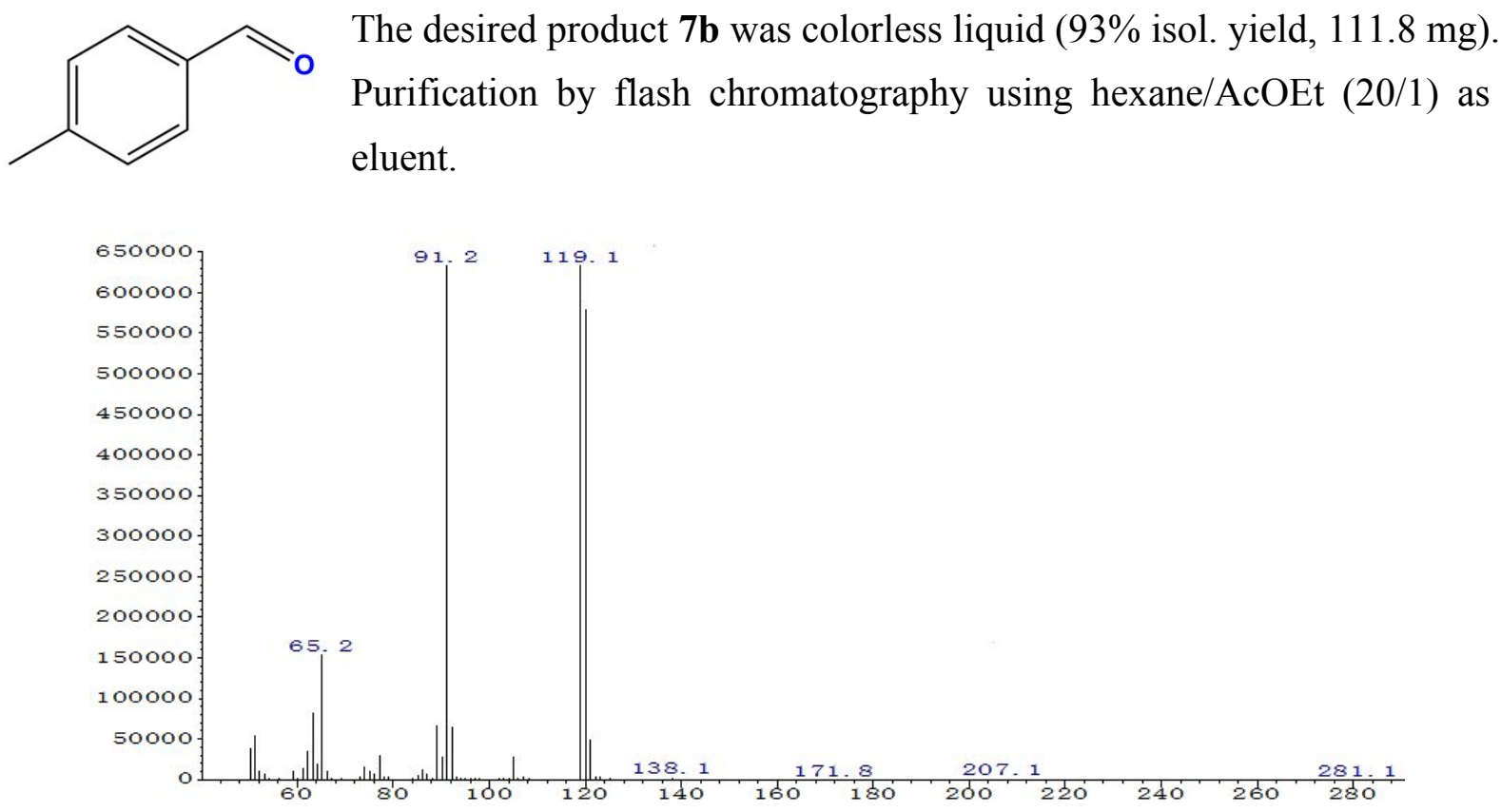


\section{Benzeneacetaldehyde ${ }^{4}(8 b)$}
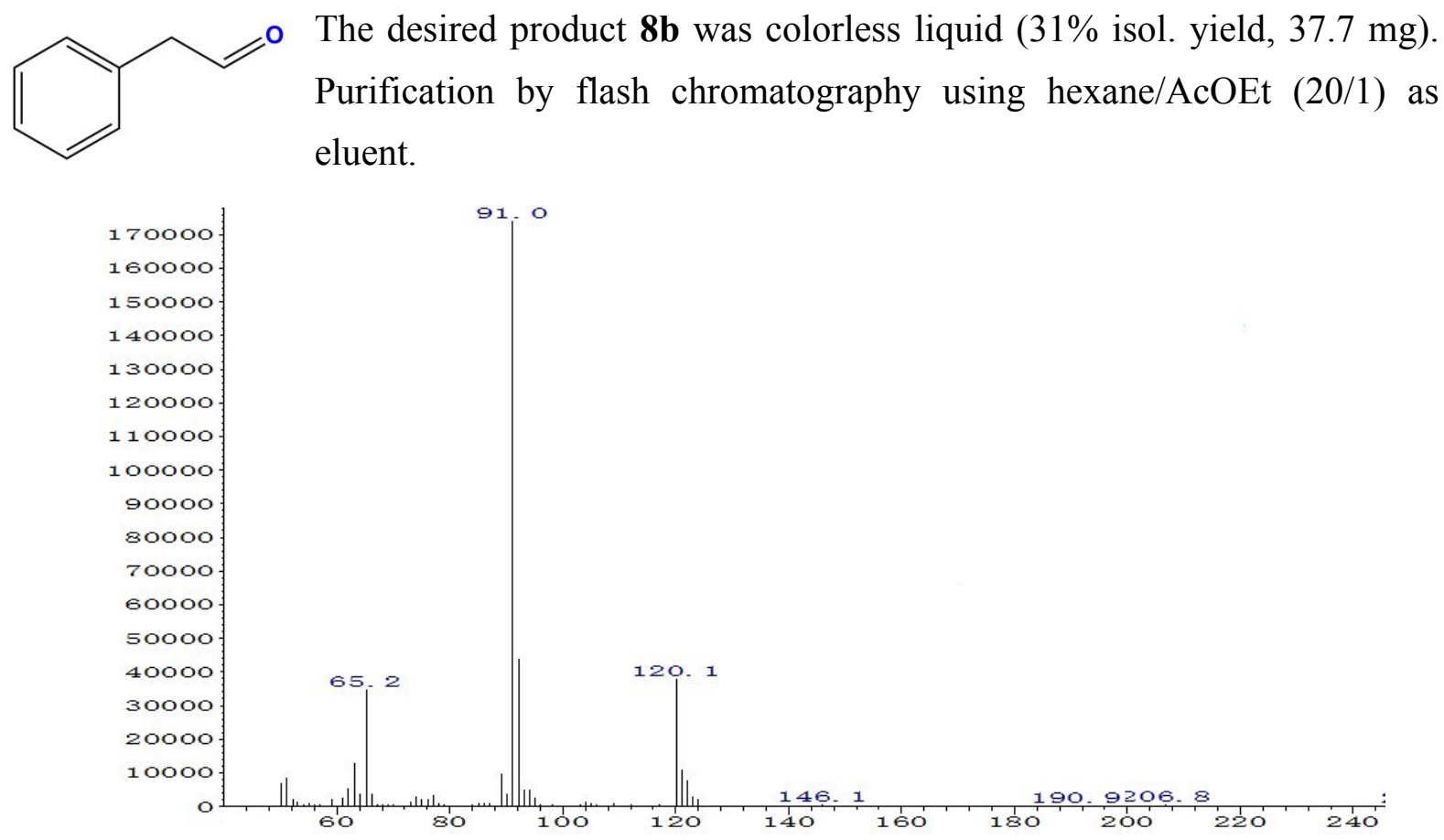

\section{Acetophenone $^{5}$ (9b)}
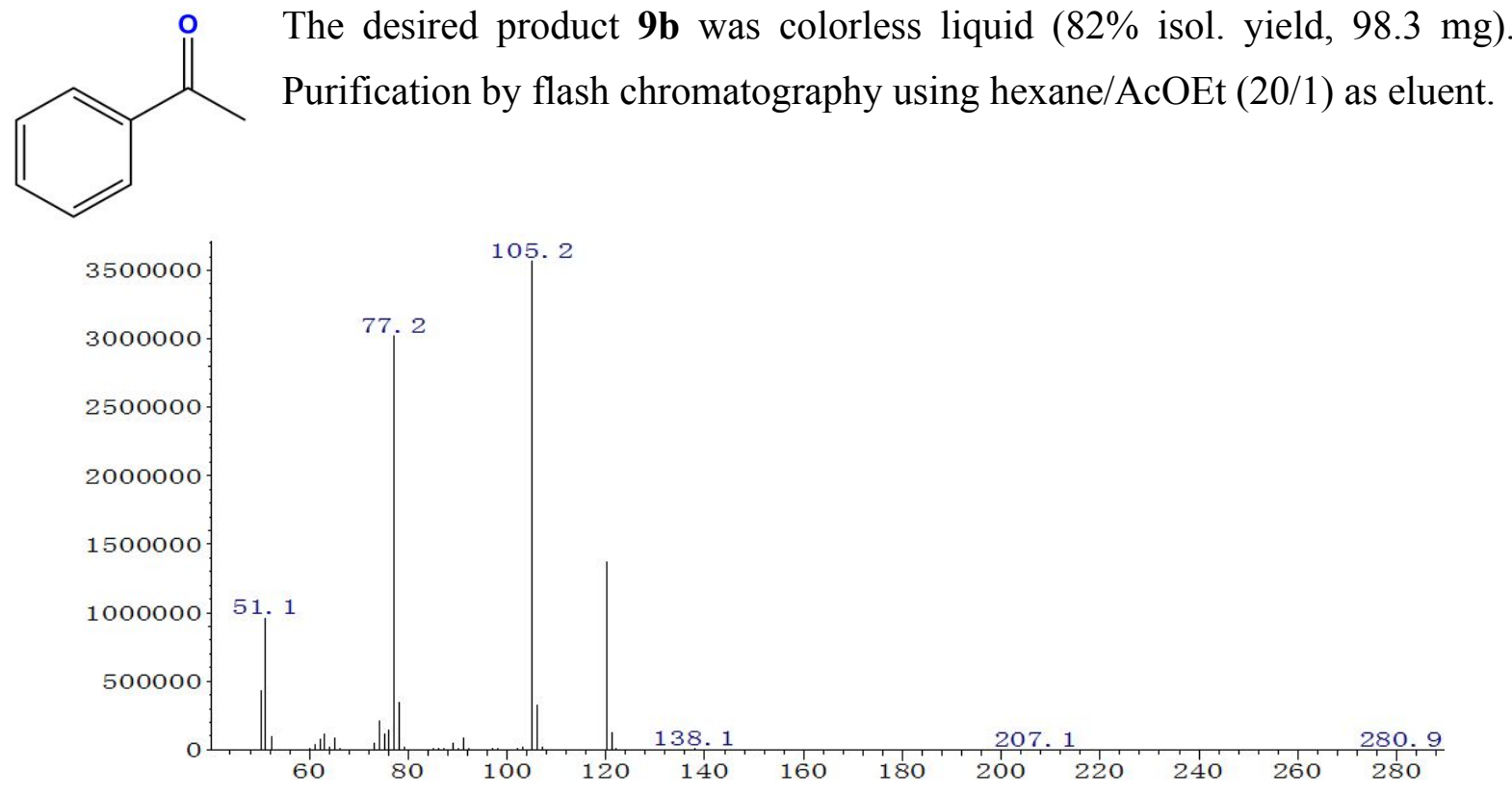
<smiles>O=C(c1ccccc1)c1ccccc1</smiles>

The desired product 10b was colorless liquid (92\% isol. yield, 168.3 mg). Purification by flash chromatography using hexane/AcOEt $(20 / 1)$ as eluent.

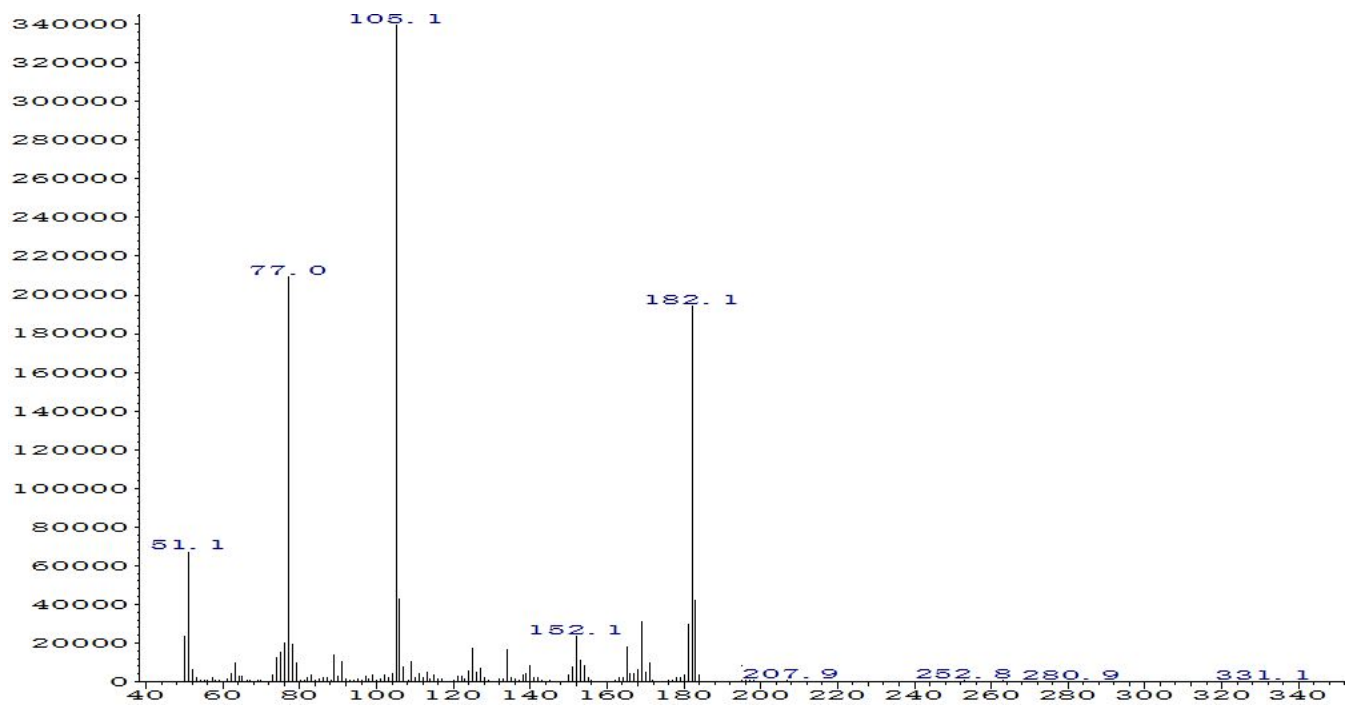

\section{Gram-Scale Synthesis of $1 b$}<smiles>C/C=C\c1ccccc1</smiles><smiles>CC(C)(C)OCCCO</smiles>
Light, air, $20^{\circ} \mathrm{C}$

$10 \mathrm{mmol}, 1.04 \mathrm{~g}$

$10 \mathrm{mmol}(1.04 \mathrm{~g}) \mathbf{1 a}, 100 \mathrm{~mL}$ of $\mathrm{CH}_{3} \mathrm{CH}$ and $120 \mathrm{mmol} \mathrm{H}_{2} \mathrm{O}_{2}$ were sequentially added into a $250 \mathrm{ml}$ flask. Subsequently, the mixture was illuminated by the high pressure mercury lamp for $42 \mathrm{~h}$ with continuous stirring. The reaction temperature was kept at $20{ }^{\circ} \mathrm{C}$ by a circulating bath and an air fan. The conversion of $\mathbf{1 a}(97 \%)$ and the selectivity of $\mathbf{1 b}(97 \%)$ were detected by gas chromatography. 


\section{Supplementary Charactrization and Informantion}

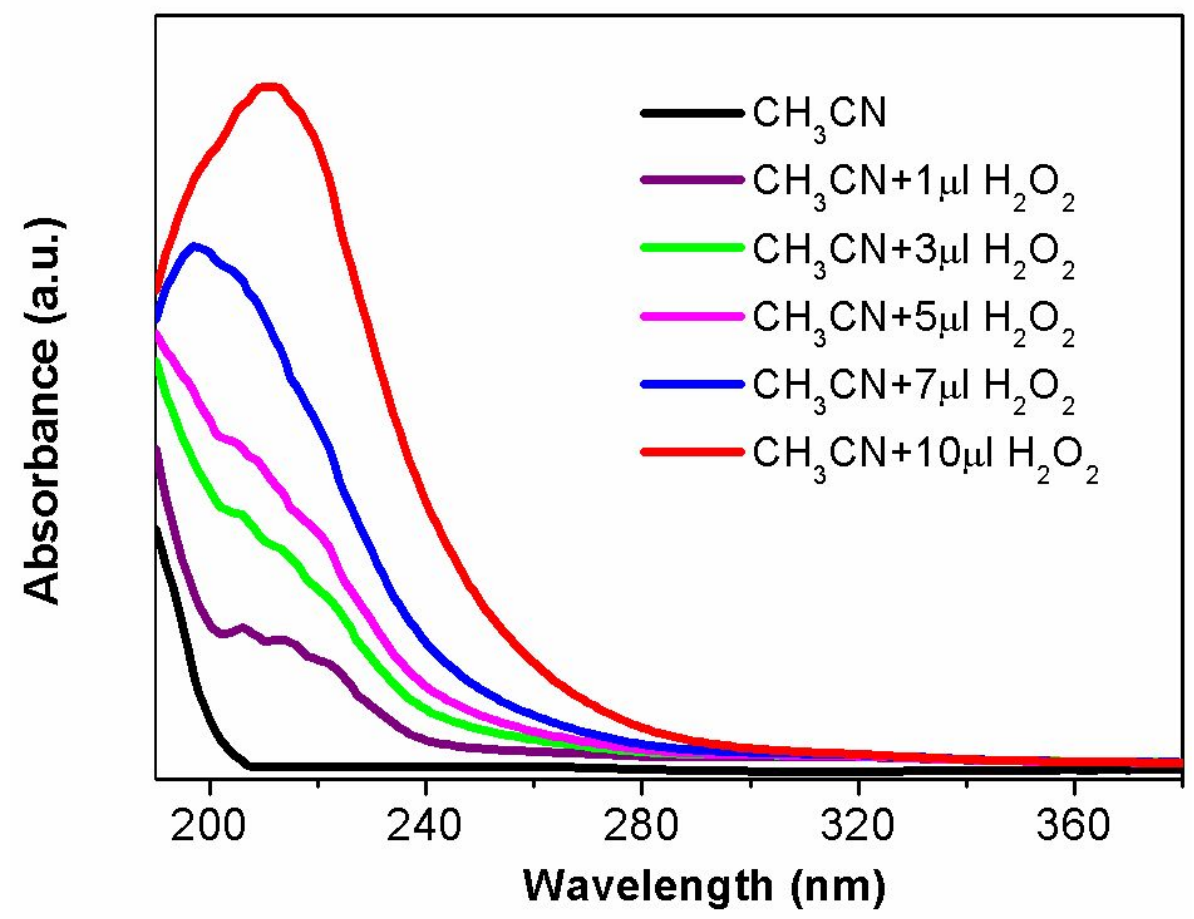

Figure S3. UV-Vis absorption spectra of $\mathrm{H}_{2} \mathrm{O}_{2}$ acetonitrile solutions with diverse concentrations. 


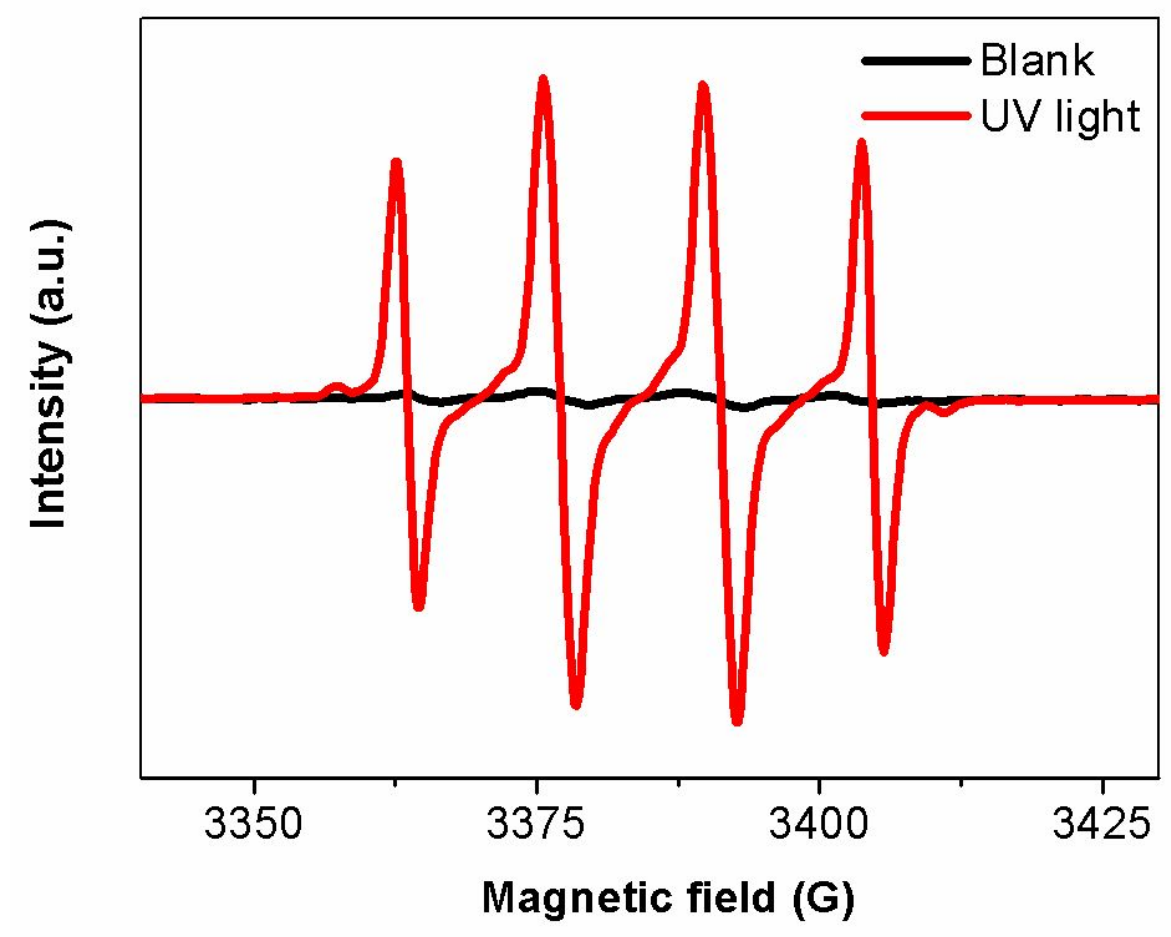

Figure S4. DMPO spin-trapping ESR spectra for DMPO - $\cdot \mathrm{OH}$ of $\mathrm{H}_{2} \mathrm{O}_{2}$ acetonitrile solutions under UV light irradiation or without light irradiation (Blank). 

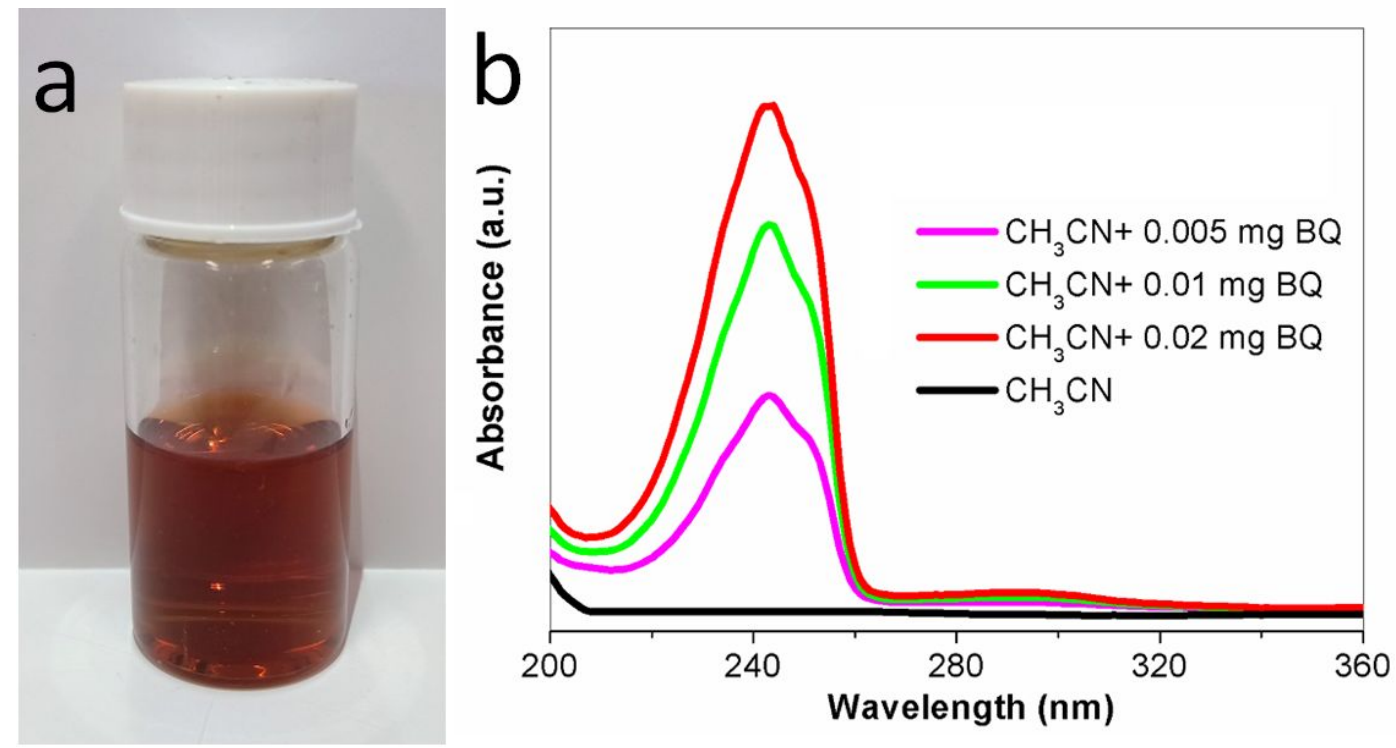

Figure S5. (a) Photograph of BQ acetonitrile solution $\left(10 \mathrm{mg} \mathrm{mL}^{-1}\right)$. (b) UV-Vis absorption spectra of different concentrations of BQ in $\mathrm{CH}_{3} \mathrm{CN}\left(1 \mathrm{~mL} \mathrm{CH}{ }_{3} \mathrm{CN}+\mathrm{x} \mathrm{mg} \mathrm{BQ}\right)$. 
Table S1. Summary of performence of literature reported for oxidation of olefins to carbonyls.

\begin{tabular}{|c|c|c|c|c|c|c|}
\hline Catalyst & Oxidant & Condition & $\begin{array}{c}\text { Time } \\
\text { (h) }\end{array}$ & $\begin{array}{c}\text { Conv. } \\
(\%)\end{array}$ & $\begin{array}{l}\text { Sel. } \\
(\%)\end{array}$ & Ref. No. \\
\hline Cataly-free & $\mathrm{H}_{2} \mathrm{O}_{2}$ & $\mathrm{UV} / 20^{\circ} \mathrm{C}$ & 8 & 96 & 93 & this work \\
\hline Cataly-free & $\mathrm{O}_{2}$ & $\mathrm{UV} /-$ & 12 & 29 & 91 & 3 \\
\hline $\mathrm{g}-\mathrm{C}_{3} \mathrm{~N}_{4}$ & $\mathrm{H}_{2} \mathrm{O}_{2}$ & Light $/ 70^{\circ} \mathrm{C}$ & 24 & 19 & 69 & 4 \\
\hline $\mathrm{V}_{2} \mathrm{O}_{5} / \mathrm{g}-\mathrm{C}_{3} \mathrm{~N}_{4}$ & & & 1 & 98 & 88 & \\
\hline $\mathrm{Fe}(\mathrm{OTf})_{3}-\mathrm{L} 1$ & $\mathrm{O}_{2}$ & $60^{\circ} \mathrm{C}$ & 6 & \multicolumn{2}{|c|}{ Yield 77\% } & 5 \\
\hline $\mathrm{Cu}-\mathrm{COF}_{\mathrm{HX}}$ & TBHP & $40^{\circ} \mathrm{C}$ & 5 & 44 & 72 & 6 \\
\hline $\mathrm{Cu}-\mathrm{COF}_{\mathrm{HX}}$ & & & & 76 & 76 & \\
\hline $\mathrm{FePcF}_{16} / \mathrm{Et}_{3} \mathrm{SiH}$ & $\mathrm{O}_{2}$ & RT & 6 & \multicolumn{2}{|c|}{ Yield $82 \%$} & 7 \\
\hline GO-[Mn(TPyP)tart] & $\mathrm{O}_{2}$ & $60^{\circ} \mathrm{C}$ & 2 & 100 & 11 & 8 \\
\hline $\mathrm{Co}(\mathrm{bpo})_{2}$ & ТВHP & $80^{\circ} \mathrm{C}$ & 8 & 80 & 43 & 9 \\
\hline $\mathrm{Cu}(\mathrm{bpo})_{2}$ & & & & 100 & 64 & \\
\hline $\mathrm{Fe}\left(\mathrm{BF}_{4}\right)_{2} \cdot 6 \mathrm{H}_{2} \mathrm{O} /$ pyridine- 2,6 & PHIO & RT & 20 & 100 & 92 & 10 \\
\hline \multicolumn{7}{|l|}{-dicarboxylic acid } \\
\hline $\mathrm{Cu}(\mathrm{II})-\mathrm{L}$ & $\mathrm{H}_{2} \mathrm{O}_{2}$ & $40^{\circ} \mathrm{C} / \mathrm{ph}=2.0$ & 12 & 78 & 91 & 11 \\
\hline Nano- $\gamma-\mathrm{Fe}_{2} \mathrm{O}_{3}$ & $\mathrm{H}_{2} \mathrm{O}_{2}$ & $75^{\circ} \mathrm{C}$ & 5 & \multicolumn{2}{|c|}{ TON 19\% } & 12 \\
\hline $\mathrm{Mg}_{1-\mathrm{x}} \mathrm{Cu}_{\mathrm{x}} \mathrm{Fe}_{2} \mathrm{O}_{4}$ & $\mathrm{H}_{2} \mathrm{O}_{2}$ & $80^{\circ} \mathrm{C}$ & 8 & 21 & 77 & 13 \\
\hline Nano-RuHAP & $\mathrm{NaIO}_{4}$ & RT & 2 & \multicolumn{2}{|c|}{ Yield 66\% } & 14 \\
\hline
\end{tabular}

Note: There is no direct comparison between the activity of different olefin oxidation reaction systems due to the various reaction conditions (type (light/heat) and intensity of driving force, oxidation, solvent, temperature and so on). The purpose of the table is to help readers understand the status of olefins oxidation reaction. 


\section{References}

(1) Zhao, Z. K. ; Wang, X. H. Supported phosphotungstic acid catalyst on modified activated carbon for Friedel-Crafts alkenylation of diverse aromatics to their corresponding $\alpha$-arylstyrenes. Appl. Catal. A, Gen. 2015, 503, 103-110.

(2) Daneshvar, N.; Behnajady, M. A.; Mohammadi, M. K. A.; Dorraji, M. S. S. UV/ $\mathrm{H}_{2} \mathrm{O}_{2}$ Treatment of Rhodamine B in Aqueous Solution: Influence of Operational Parameters and Kinetic Modeling. Desalination. 2008, 230, 16-26.

(3) Ren, Y.; Che, Y.; Ma, W.; Zhang, X.; Shen, T.; Zhao, J. Selective Photooxidation of Styrene in Organic-water Biphasic Media. New J. Chem. 2004, 28, 1464-1469.

(4) Zou, H.; Xiao, G. S.; Chen, K. H.; Peng, X. H. Noble Metal-Free $\mathrm{V}_{2} \mathrm{O}_{5} / \mathrm{g}-\mathrm{C}_{3} \mathrm{~N}_{4}$ Composites for Selective Oxidation of Olefins Using Hydrogen Peroxide as An Oxidant. Dalton Trans. 2018, 47, 13565-13572.

(5) G.-de-Castro, A.; Xiao, J. L. Green and Efficient: Iron-Catalyzed Selective Oxidation of Olefins to Carbonyls with $\mathrm{O}_{2}$. J. Am. Chem. Soc. 2015, 137, 8206-8218.

(6) Mu, M. M.; Wang, Y. W.; Qin, Y. T.; Yan, X. L.; Li, Y.; Chen, L. G. Two-Dimensional Imine-Linked Covalent Organic Frameworks as a Platform for Selective Oxidation of Olefins. ACS Appl. Mater. Interfaces. 2017, 9, 22856-22863.

(7) Puls, F.; Knölker H.-J. Conversion of Olefins into Ketones by an Iron-Catalyzed Wacker-type Oxidation using Oxygen as the Sole Oxidant. Angew. Chem. Int. Ed. 2018, 57, 1222 -1226.

(8) Berijani, K.; Farokhi, A.; Hosseini-Monfared, H.; Janiak, C. Enhanced Enantioselective Oxidation of Olefins Catalyzed by Mn-porphyrin Immobilized on Graphene Oxide. Tetrahedron. 2018, 74, 2202-2210.

(9) Lashanizadegan, M.; Alavijeh, R. K.; Anafcheh, M. Facile Synthesis of Co(II) and Cu(II) Complexes of 2-hydroxybenzophenone: An Efficient Catalyst for Oxidation of Olefins and DFT Study. J. Mol. Struct. 2017, 1146, 450-457.

(10) Chowdhury, A. D.; Ray, R.; Lahiri, G. K. An Rron Catalyzed Regioselective Oxidation of Terminal Alkenes to Aldehydes. Chem. Commun., 2012, 48, 5497-5499.

(11) Li, X. H.; Mi, C.; Liao, X. H.; Meng, X. G. Selective Oxidation of Aromatic Olefins Catalyzed by Copper(II) Complex in Micellar Media. Catal. Lett. 2017, 147, 2508-2514.

(12) Shi, F.; Tse, M. K.; Pohl, M.-M.; Brückner, A.; Zhang, S.; Beller, M. Tuning Catalytic Activity Between Homogeneous and Heterogeneous Catalysis: Improved Activity and Selectivity of Free Nano-Fe $\mathrm{O}_{2}$ in Selective Oxidations. Angew. Chem. Int. Ed. 2007, 46, 8866 -8868.

(13) Cai, X.; Wang, H.; Zhang, Q.; Tong, J. Selective oxidation of styrene efficiently catalyzed by spinel $\mathrm{Mg}-\mathrm{Cu}$ ferrite complex oxides in water. J. Sol-Gel. Sci. Technol. 2014, 69, 33-39.

(14) Ho, C.-M.; Yu, W.-Y.; Che, C.-M. Ruthenium Nanoparticles Supported on Hydroxyapatite as an Efficient and Recyclable Catalyst for cis-Dihydroxylation and Oxidative Cleavage of Alkenes. Angew. Chem. Int. Ed. 2004, 43, 3303-3307. 